\title{
High aluminum levels in cerebrospinal fluid of patients with neurodegenerative diseases
}

\begin{abstract}
Aluminum is the most abundant metal on earth. It is not known to have any biological metabolism; conversely it has a toxic effect that has been related to several damages including some neurodegenerative diseases. We sampledcerebrospinal fluid (CSF) in 141 patients with different chronic diseases, assessing the levels of aluminum contained. Our aim was to assess differences in aluminum levels between neuro-degenerative and nonneurodegenerative diseases. We found that patients with neurodegenerative diseases have higher levels of aluminum in cerebrospinal fluid than other non-degenerative diseases. These findings support previous descriptions of a chronic life-time aluminum accumulation in CSF as an environmental contributor to the Patophysiology of neurodegeneration. While aluminum and neurodegenerative diseases have already been correlated in previous studies, this report is, to the best of our knowledge, the first that directly correlates levels of aluminum in CSF with clinical status. Further investigation based on these findings has to be done in order to determine if this correlation is causality of specific diseases. In the meantime we encourage a wider sampling of aluminum (and other metals) in CSF in both patients with a neurodegenerative disease and healthy population as well as the analysis of aluminum-containing products.
\end{abstract}

\author{
Volume 3 Issue 3 - 2017
}

\author{
Ruiz-Navarro F, Kobinia G \\ Medical Doctor,Austrian Society for Regenerative Medicine, \\ Austria
}

Correspondence: Francisco Ruiz-Navarro, Medical Doctor, Research Department, Austrian Society for Regenerative Medicine, Wolzeile 3/Top 2.I,Vienna, orcid.org/0000-000I-5277687X,Austria, Tel +43676421 7568 Email ruiznavarro.md@gmail.com

Received: June 18,2017 | Published: July 06, 2017

\section{Introduction}

Aluminum is the most abundant metal on earth and is not known to have any biological metabolism in any living species. ${ }^{1}$ On the contrary, several studies have described its toxicity to the organic system although the mechanism is not fully understood. ${ }^{2-7}$ The deleterious effect of this metal has been discussed for decades, the first time 40 years ago in an animal model $^{8}$ with several studies linking its presence in serum, cerebrospinal fluid (CSF) and central nervous system (CNS) to several neurodegenerative diseases (ND) such as Alzheimer's disease (AD), ${ }^{5,9-15}$ and Amyotrophic Lateral Sclerosis (ALS). ${ }^{12,16-23}$ There have been previous correlations of other metals metabolism and neurodegenerative diseases that encourage the study of aluminum in CNS and its contribution in neurodegeneration. ${ }^{24-27}$ The chronic accumulation of aluminum in the CNS is the principal mechanism of toxicity proposed. In this process, small amounts of aluminum ingested over the years accumulate in the brain tissue and form deposits that activate apoptosis and promote degeneration that leads to neuron loss. This toxic effect has been described with injected and ingested aluminum in animal models by different authors ${ }^{14,28-32}$ and some factors have being described to determine the grade of neurotoxicity, such as age and renal function. ${ }^{33}$ Furthermore, there are groups already testing ways to protect neuronal tissue from the effects of aluminum. ${ }^{34,35}$ Despite the evidence that links aluminum to CNS damage, the controversy regarding the participation of aluminum in the physiopathology of neurodegenerative diseases remains. The fact that the aluminum industry has been and still is one of the most profitable industries worldwide may contribute to this lasting controversy. To support the hypothesis of aluminum contributing to neurodegeneration, we assumed that a measurement in CSF that is in direct contact and constantly exchanges substances with cerebral tissue, would provide a more accurate proof of the accumulation of aluminum in cerebral tissue. Furthermore, when correlating these levels with other non-neurodegenerative diseases (as a control group) and with the patients' clinical status, the causality of aluminium can be better accounted for

\section{Methods}

After informed consent was given by the patient or their legal guardian in accordance with the International Regulations of the World Medical Association declaration of Helsinki, we sampled CSF from 141 patients that were seeking autologous bone marrow transplantation for a neurological disease. After skin sterilization with not-stained Isozid- $\mathrm{H}^{\circledR}$ solution (Hexetidin, 2-Propanolol, 1-Propanolol), a lumbar puncture (L3-L4) was performed with a 22 Gauge Spinocan ${ }^{\circledR}$ (Fa. Braun) needle for adults. Two ml of CSF were slowly withdrawn in a $2 \mathrm{ml}$ plastic syringe before the infusion of bone marrow-derived mononuclear cells (BM-MNCs) into the CSF. The syringe was closed using a plastic cap and immediately sent to the laboratory (Synlab Labor München-Zentrum Medizinisches Versorgungszentrum GbR). Aluminum levels were measured by a Varian Graphite furnace atomic-absorption spectrometer (GFAAS) with background signal correction based on the Zeeman Effect (Model AA220 Z or Model AA280 Z with urine calibrators and controls) after dilution with deionized water/Triton-X-100-Solution. The minimum level of aluminum detected by this method was $2 \mu \mathrm{g} / \mathrm{l}$. Patient's bone marrow (BM) was harvested from the posterior superior iliac crest and underwent a 30 minutes on-site cell separation with a closed system $\left(\right.$ Sepax $\left.\mathrm{II}^{\circledR}\right)$ that uses density centrifugation with a fixed $10 \%$ reduction rate. ${ }^{36}$ Samples of BM before separation (BMB) and after separation (BMA) were also submitted for laboratory analysis, where the number of $\mathrm{CD} 34+$ cells $/ \mu 1$ was assessed according to the ISHAGE guidelines ${ }^{37}$ with the Stem-kit Beckman Coulter (single platform principle with CD45FITC/CD34 PE detector). Vitality was measured with 7-Aminoactinomycin D (7-AAD) dye by conventional flow cytometer, which determines the integrity of the nuclei. The number of leukocytes was determined by means of a conventional flow cytometer. The concentration factors $(\mathrm{CF})$ of CD34+ cells $/ \mu 1$ and leukocytes/nl were mathematically assessed resulting in the quotient of BMA divided by the BMB value for each patient. The reduction in vitality was determined with the same mathematical method. After analyzing the distribution of aluminum in the complete sample, a 
cutoff point of $12 \mu \mathrm{g} / \mathrm{l}$ was determined in or der to divide the sample in two groups. The groups were compared to each other (groupbelow $12 \mu \mathrm{g} / 1$ and group over $12 \mu \mathrm{g} / \mathrm{l}$ ) using non-parametric test (Levene's T test for equality of variances and $\mathrm{T}$ test for equality of means, except for the variables that did not show a normal distribution, in which case we used the Wilcoxon-Mann-Whitney test). Confidence intervals of $95 \%$ were used, the null hypothesis was rejected when a significance of $\mathrm{p}=0.05$ was reached and when rejected, the test was considered statistically significant. Regression models were performed to the variables. Graphs were prepared and analyzed using the IBM SPSS statistics software version 2.0.

\section{Results}

Detectable levels of aluminum were found in $86 \%$ of the patients. We found that neurodegenerative diseases have higher levels of

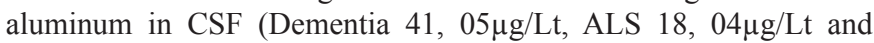
MS25, $9 \mu \mathrm{g} / \mathrm{Lt}$ ). Furthermore, the levels are statistically significantly higher in neurodegenerative diseases than in other diseases $(18,49 \mu \mathrm{g} /$ Lt vs $11,08 \mu \mathrm{g} / \mathrm{Lt} . \mathrm{p}=0,023$ ) (Figure 1). Higher levels of aluminum were related to a less efficient response to treatment ("worse" in the graphic) with BM-MNC. This result, however, cannot be considered statistically significant $(\mathrm{p}=0.157)(14,2 \mu \mathrm{g} / \mathrm{Lt}$ vs $20,09 \mu \mathrm{g} / \mathrm{Lt})$ (Figure 2 ). We divided the complete sample into two groups depending on whether they were above or under $12 \mu \mathrm{g} / 1$ aluminum levels in CSF. A comparison was made between these levels in CSF and the number and quality of mononuclear cells in the BM used for the transplantation. It was found that lower levels of CD34+ $(549,5$ cells/ $\mu 1$ vs. 838,4 cells/ $\mu 1)$ and low vitality $(70,05 \%$ vs $70,3 \%)$ in the BM sample swere related to higher levels of aluminum in CSF $(>12 \mu \mathrm{g} / \mathrm{l})(\mathrm{p}=0,005$ and $\mathrm{p}=0,018$ respectively) (Figure $3 \& 4$ ) with statistical significance. The group above $12 \mu \mathrm{g} / 1$ also had a lower concentration capacity, which shows when comparing the concentration factor of CD34+ before and after the closed centrifugation. This group also displayed a higher reduction in vitality compared to the group with less than $12 \mu \mathrm{g} / 1$ (Figure $5 \& 6$ ). Finally, regarding the cell values in the BM, the group with more than $12 \mu \mathrm{g} / 1$ aluminum in CSF was also significantly related to higher levels of leukocytes in the BM $(\mathrm{p}=0,001)$ (Figure 7).

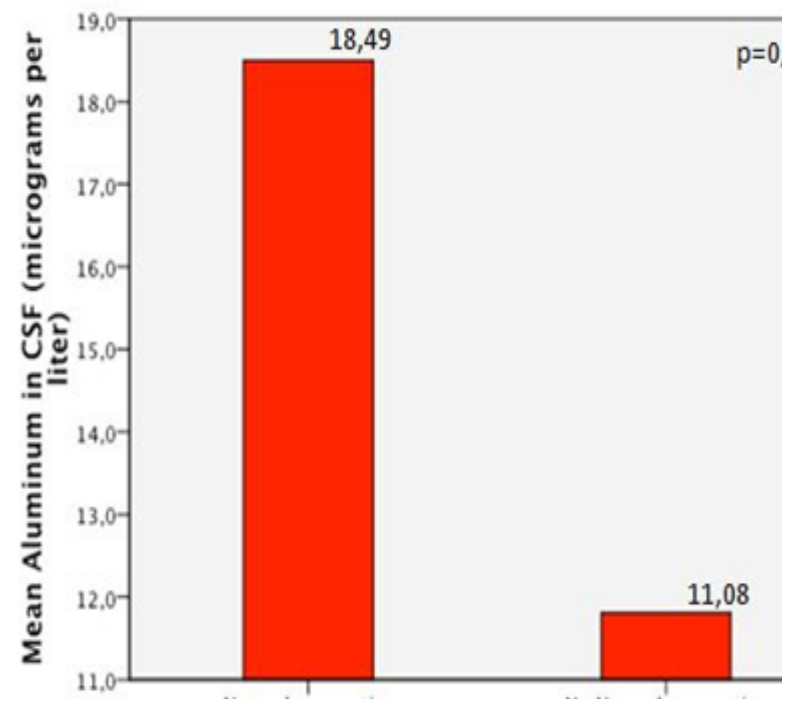

Figure I Statistical significant higuer mean level of aluminum in CSF in patients with neurodegenerative diseases compared to patients with non neurodegenerative disease.

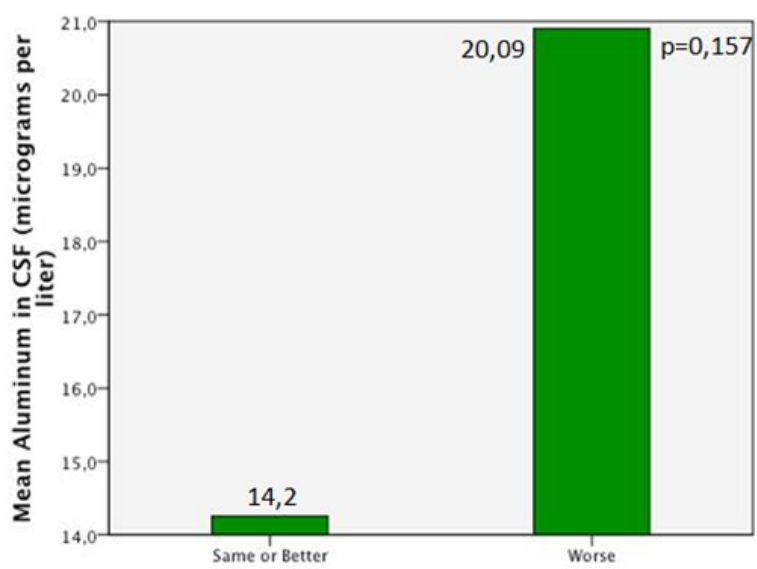

Figure 2 Patients with higuer mean levels of aluminum in CSF responded less efficiently to the treatment with BM-MNC ("worse").

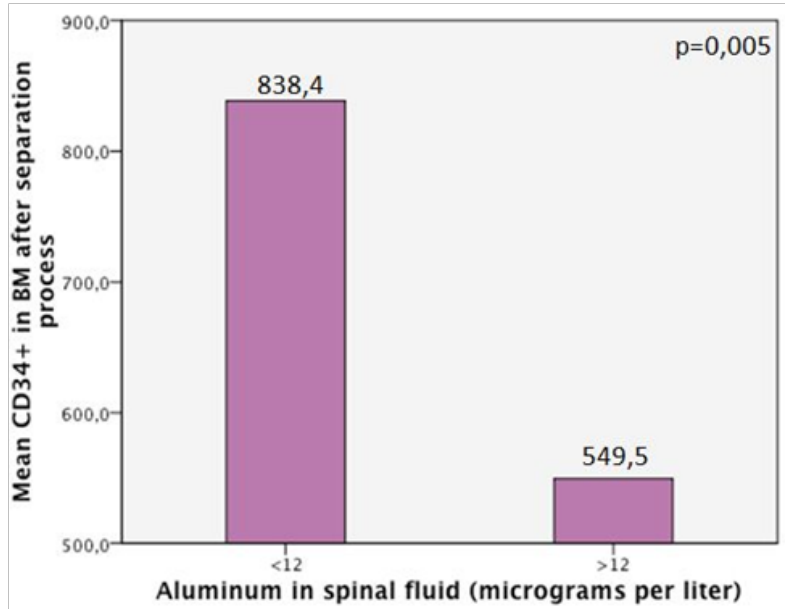

Figure 3 An empirical cutoff point in the sample was made (I 2 micrograms per liter). Patients with aluminum in CSF under 12 had higuer counts of CD34+ cells in BM (bone marrow) in the sample taken after the separation process of the cells.

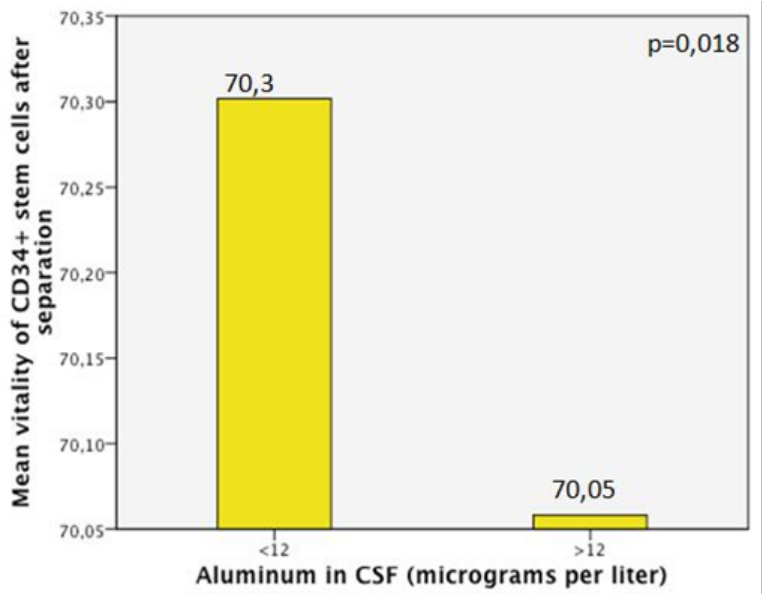

Figure 4 An empirical cutoff point in the sample was made (12 micrograms per liter). Patients with aluminum in CSF under 12 had higuer vitallity in the CD34+ cells of the BM (bone marrow) in the sample taken after the separation process of the cells. 


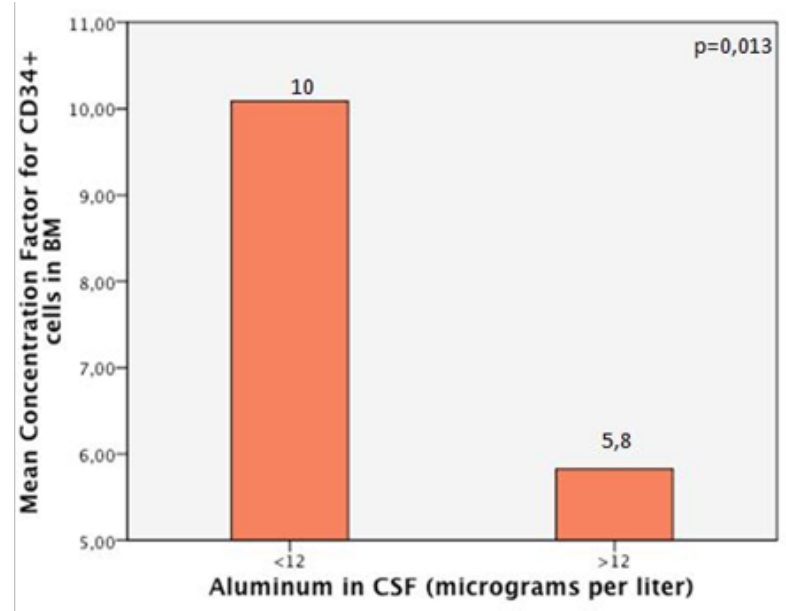

Figure 5 An empirical cutoff point in the sample was made (12 micrograms per liter). Patients with aluminum in CSF under 12 had a higuer concentration factor after separation process.

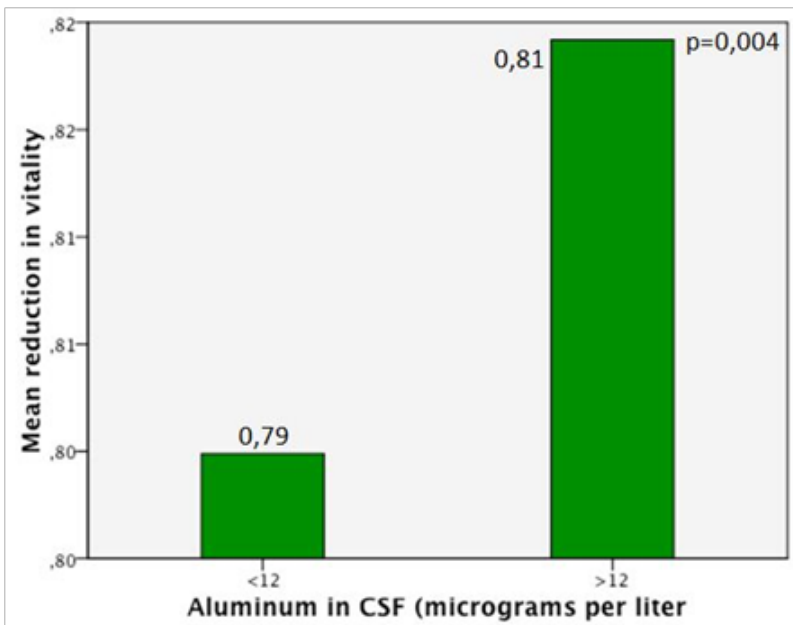

Figure 6 An empirical cutoff point in the sample was made (1 2 micrograms per liter). Patients with aluminum in CSF under 12 had less reduction in the vitallity of CD34+ derived from BM (Bone Marrow) cells after separation process.

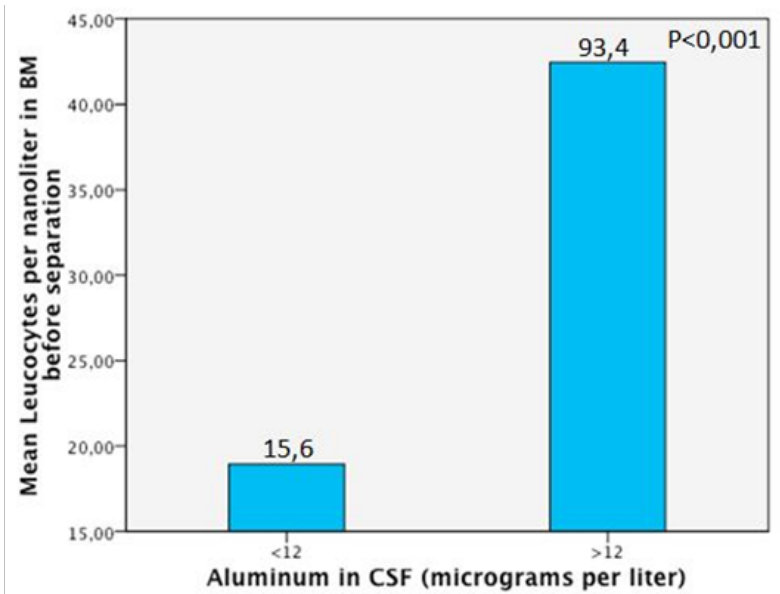

Figure 7 An empirical cutoff point in the sample was made (12 micrograms per liter). Patients with aluminum in CSF under 12 had lower mean of leucocytes in BM (bone marrow).

\section{Discussion}

The fact that we have patients without aluminumin CSF (14\%) proves that our methodology of withdrawing the samples does not influence aluminum levels at all; however, $86 \%$ of patients had some trace of aluminum in the CNS. The patients are from different regions in the world bringing us to the assumption that the contact with aluminum may not be exclusively from work or specific local diets, otherwise is pointing as a wide environmental presence in several human activities. Previous reports and basic research in the chemistry of aluminum had described none biological function of aluminum in the organic systems. Therefore, we assumed that any aluminum presence in the CSF is abnormal and potentially hazardous to every person regardless of their diagnosis and health status. There are descriptions of which levels of aluminum in serum would be hazardous for a regular person in the case of acute intoxication, which could eventually also be reflected in CSF. However, there are no current descriptions of the minimal amount of aluminum in CSF that could actually cause chronic damage; hence we determined a level of $12 \mu \mathrm{g} / \mathrm{l}$ in CSF as an empirical cutoff point for an extremely deleterious effect, taking into account the mean of our sample as a reference. It is important to stress that even though we took this value as a reference point, it is hypothesized that even lower levels of aluminum can cause deleterious effects in the organisms by starting a cascade of neuron damage. Lack to improve the disease after BM transplantation was associated with a tendency to have higher levels of aluminum thought it did not reach statistical significance $(p=0.157)$. We therefore recommend further investigations of these correlations using a better selected sample (Figure 2). A hypothesis on this phenomenon is that a chronic accumulation of aluminum is not limited to one tissue. As a consequence, not only the CSF is chronically damaged but also other tissues in which deposits of metals or other substances are probable, such as in the BM. We understand that since aluminum was not measured in the BM its correlation with CSF do not automatically allow conclusions for the participation of the BM in the pathophysiology and the clinical status of a neurodegenerative disease. Nevertheless, we can assume that high levels of aluminum in CSF could also represent a complete body intoxication including the BM causing low and abnormal production of stem cells and other cells in the BM.

This abnormal and/or reduced production of stem cells in the bone marrow would certainly interfere with the normal mechanisms of the body to overcome an injury. This process has been previously described to occur in the case of a neurological injury. In this case, stem cells from the BM migrate to the site of injury in the CNS and try to overcome the damage by different secretion factors and through the activation of functions in the local neural stem cells. ${ }^{38-40}$ This hypothesis should be further investigated. Supporting the above mentioned, we found that low levels of $\mathrm{CD} 34+$ cells/ $\mu 1$ and low vitality in the BM are statistically significantly related to high levels of aluminum in CSF, probably indicating an intoxication of the whole organism. The $\mathrm{CD} 34+$ cells demonstrate the presence of hematopoietic stem cells (HSCs) in the BM; the HSCs together with other BMMNCs, such as mesenchymal stem cells (MSCs), are the ones that cause beneficial effects in neural tissue repair. ${ }^{41-45}$ Furthermore, patients with higher levels of aluminum in CSF are the ones with lower levels of concentration factor for BM-MNCs and suffered a greater vitality reduction after the separation process (Figures 6 \& 7). This could reinforce the hypothesis that a poor quality of cells in the bone marrow of more severely intoxicated patients makes BM- 
MNCs abnormally fragile and unable to support a minimal process of manipulation such as concentration by a centrifuge.

Additionally, we found that high levels of aluminum are also related to high level of leukocytes in the BM. The immune is responding to the presence of aluminum in the body, which could be consider a proof of chronic inflammatory reaction (Figure 6). Based on these findings we can propose an additional pathogenic mechanism of aluminum in neurodegenerative diseases. It is probable that aluminum is one of the external factors that directly affect the CNS but also the BM through the life-accumulation mechanism. Several scientific groups have described that, among other functions, the bone marrow serves to mobilize and migrate BM-MNCs to injured tissues so that they can participate in the repair process. In parallel to these considerations, there are a number of recent studies that have associated the development of several degenerative diseases with a reduced number of circulating SCs in peripheral blood. This data together provide a possible understanding of degenerative diseases thatdo not just develop due to intrinsic cellular loss or external factors, but also following an imbalance between cellular loss and tissue renewal. ${ }^{40,45}$ supporting this hypothesis, in our cohort, patients that have high levels of aluminum in CSF and therefore in neurons are probably producing a strong signal to the $\mathrm{BM}$ asan attempt to renew the damaged neurons with mobilization of SCs from the BM to the injured site. This is why the BM should increase the production of $\mathrm{SCs}$ and serve to explain the high content of CD34+ cells/ $\mu$ in the BM aspiration before separation.

However, the lack of migrating capacity or functional deficiency, not measured but assumed by the low resistance to centrifuge, as well as the drastic reduction ofCD34+ cells/ $\mu 1$ after separation in patients with high aluminum levels in CSF, probably cause an imbalance in tissue renewal. This deficient production of SC may be linked to the presence of aluminum in BM as an inflammatory factor, which means that leukocytes production and other inflammatory factors are activated and interfere in the migration capacity. These assumptions should be further confirmed by sampling SCs levels in the peripheral blood and $\mathrm{BM}$ of the same patient. ${ }^{46}$ Moreover, this analysis could identify BM as another possible indirect biomarker in some neurodegenerative diseases.

\section{Conclusion}

Aluminum in the majority of patients regardless of their clinical diagnosis. Because of the toxic profile of aluminum, only aminimal presence of aluminum in CSF constitutes a potential harm. Furthermore, there is a clear prevalence of high aluminum levels in patients with neurodegenerative diseases, as has been shown by previous studies. $8,11,13,14,20,28,30,32$ We assumed that any aluminum presence in the CSF was abnormal and potentially hazardous to every person regardless of their diagnosis and health status. This study is the first description of a statistically significant relationship between high levels of aluminum in CSF and pathogenesis in humans with neurodegenerative diseases. There is an urgent necessity to allocate research funds supporting research on aluminum's contribution to neurodegenerative diseases. Furthermore, studies with larger samples that include healthy control groups are needed in order to collect more information on aluminum neurotoxicity in humans and the development of diseases.

Furthermore, it seems that aluminum is not just causing specific intoxication of one single organ, its wide action attacks also stem cells activity, destroying the basic mechanism of regeneration in humans and ultimately life. Moreover, studies investigating possible treatments for aluminum intoxication in CNS are necessary. A matter of fact is that little is known about detoxification of aluminum from the CNS. Hence, detoxification may become a field of increasing importance in clinical practice. What is also highly important for public health are aluminum screenings in the general healthy population to assess and prevent lifetime accumulation and the development of related diseases.

\section{Acknowledgements}

None.

\section{Conflict of interest}

The author declares no conflict of interest.

\section{References}

1. Shaw CA, Seneff S, Kette SD, et al. Aluminum-Induced Entropy in Biological Systems: Implications for Neurological Disease. J Toxicol. 2014;2014:e491316.

2. Exley C, Burgess E, Day JP, et al. Aluminum toxicokinetics. J Toxicol Environ Health. 1996;48(6):569-584

3. Exley C. The coordination chemistry of aluminium in neurodegenerative disease. Coord Chem Rev. 2012;256(19-20):2142-2146.

4. Exley C, Birchall JD. The cellular toxicity of aluminium. J Theor Biol. 1992;159(1):83-98.

5. Exley C, Esiri MM. Severe cerebral congophilic angiopathy coincident with increased brain aluminium in a resident of Camel ford, Cornwall, UK. J Neurol Neurosurg Psychiatry. 2006;77(7):877-879.

6. Krewski D, Yokel RA, Nieboer E, et al. Human health risk assessment for aluminium, aluminium oxide, and aluminium hydroxide. $J$ Toxicol Environ Health B Crit Rev. 2007;10(1):1-269.

7. Maya S, Prakash T, Madhu KD, et al. Multifaceted effects of aluminium in neurodegenerative diseases: A review. Biomed Pharmacother. 2016;83:746-754.

8. Tomljenovic L. Aluminum and Alzheimer's disease: After a Century of Controversy, Is there a Plausible Link? J Alzheimers Dis. 2011;23(4):567-598.

9. Strunecká A, Patocka J. Reassessment of the role of aluminum in the development of Alzheimer's disease. Cesk Fysiol. 1999;48(1):9-15.

10. Walton JR, Wang MX. APP expression, distribution and accumulation are altered by aluminum in a rodent model for Alzheimer's disease. $J$ Inorg Biochem. 2009;103(11):1548-1554.

11. Crapper DR, Krishnan SS, Dalton AJ. Brain aluminum distribution in Alzheimer's disease and experimental neurofibrillary degeneration. Science. 1973;180(4085):511-513.

12. Garruto RM, Fukatsu R, Yanagihara R, et al. Imaging of calcium and aluminum in neurofibrillary tangle-bearing neurons in parkinsonismdementia of Guam. Proc Natl Acad Sci USA. 1984;81(6):1875-1879.

13. Kawahara M, Kato M, Kuroda Y. Effects of aluminum on the neurotoxicity of primary cultured neurons and on the aggregation of $\beta$ amyloid protein. Brain Res Bull. 2001;55(2):211-217.

14. Walton JR. Chronic Aluminum Intake Causes Alzheimer's Disease: Applying Sir Austin Bradford Hill's Causality Criteria. J Alzheimers Dis. 2014;40(4):765-838 
15. Mirza A, King A, Troakes C, et al. Aluminium in brain tissue in familial Alzheimer's disease. J Trace Elem Med Biol. 2017;40:30-36.

16. Lord C, Risi S, Lambrecht L, et al. The autism diagnostic observation schedule-generic: a standard measure of social and communication deficits associated with the spectrum of autism. J Autism Dev Disord. 2000;30(3):205-223.

17. Conradi S, Ronnevi LO, Nise G, et al. Abnormal distribution of lead in amyotrophic lateral sclerosis - reestimation of lead in the cerebrospina fluid. J Neurol Sci. 1980;48(3):413-418.

18. Kamel F, Umbach DM, Hu H, et al. Lead Exposure as a Risk Factor for Amyotrophic Lateral Sclerosis. Neurodegener Dis. 2005;2(3-4):195201.

19. Qureshi M, Brown RH, Rogers JT, et al. Serum Ferritin and Metal Levels as Risk Factors for Amyotrophic Lateral Sclerosis. Open Neurol J. 2008;2:51-54.

20. Nagata H, Miyata S, Nakamura S, et al. Heavy metal concentrations in blood cells in patients with amyotrophic lateral sclerosis. J Neurol Sci. 1985;67(2):173-178.

21. Roos PM, Vesterberg O, Syversen T, et al. Metal Concentrations in Cerebrospinal Fluid and Blood Plasma from Patients with Amyotrophic Lateral Sclerosis. Biol Trace Elem Res. 2013;151(2):159-170.

22. Yasui M, Yase Y, Ota K, et al. High aluminum deposition in the central nervous system of patients with amyotrophic lateral sclerosis from the Kii Peninsula, Japan: two case reports. Neurotoxicology. 1991;12(2):277-283.

23. Sood K, Nag D, Chandra SV. Role of aluminium in sporadic motor neuron disease. Indian J Med Res. 1990;92:9-12.

24. Costa Mallen P, Gatenby C, Friend S, et al. Brain iron concentrations in regions of interest and relation with serum iron levels in Parkinson disease. J Neurol Sci. 2017;378:38-44.

25. Deutschländer A, Konno T, Ross OA. Mitochondrial membrane proteinassociated neurodegeneration. Parkinsonism Relat Disord. 2017;39:1-3.

26. Venkatesan R, Ji E, Kim SY. Phytochemicals That Regulate Neurodegenerative Disease by Targeting Neurotrophins: A Comprehensive Review. Biomed Res Int. 2015; 2015:814068.

27. Gupta VK, Singh S, Agrawal A, et al. Phytochemicals Mediated Remediation of Neurotoxicity Induced by Heavy Metals. Biochem Res Int. 2015;2015:1-9.

28. Petrik MS, Wong MC, Tabata RC, et al. Aluminum adjuvant linked to Gulf War illness induces motor neuron death in mice. Neuromolecular Med. 2007;9(1):83-100.

29. Shaw CA, Petrik MS. Aluminum hydroxide injections lead to motor deficits and motor neuron degeneration. J Inorg Biochem. 2009;103(11):1555-1562.

30. Shaw CA, Tomljenovic L. Aluminum in the central nervous system (CNS): toxicity in humans and animals, vaccine adjuvants, and autoimmunity. Immunol Res. 2013;56(2-3):304-316.
31. Garruto RM, Shankar SK, Yanagihara R, et al. Low-calcium, highaluminum diet-induced motor neuron pathology in cynomolgus monkeys. Acta Neuropathol. 1989;78(2):210-219.

32. Luján L, Pérez M, Salazar E, et al. Autoimmune/autoinflammatory syndrome induced by adjuvants (ASIA syndrome) in commercial sheep. Immunol Res. 2013;56(2-3):317-324.

33. Yokel RA, McNamara PJ. Aluminium toxicokinetics: an updated minireview. Pharmacol Toxicol. 2001;88(4):159-167.

34. Ekong MB, Ekpo MM, Akpanyung EO, et al. Neuroprotective effect of Moringa oleifera leaf extract on aluminium-induced temporal cortical degeneration. Metab Brain Dis. 2017;32(5):1437-1447.

35. Wahby MM, Mohammed DS, Newairy AA, et al. Aluminum-induced molecular neurodegeneration: The protective role of genistein and chickpea extract. Food Chem Toxicol. 2017;107(Pt A):57-67.

36. Aktas M, Radke TF, Strauer BE, et al. Separation of adult bone marrow mononuclear cells using the automated closed separation system Sepax. Cytotherapy. 2008;10(2):203-211.

37. Sutherland DR, Anderson L, Keeney M, et al. The ISHAGE guidelines for CD34+ cell determination by flow cytometry. International Society of Hematotherapy and Graft Engineering. J Hematother. 1996;5(3):213226.

38. Shyu WC, Lin SZ, Yang HI, et al. Functional recovery of stroke rats induced by granulocyte colony-stimulating factor-stimulated stem cells. Circulation. 2004;110(13):1847-1854.

39. Cottler-Fox MH, Lapidot T, Petit I, et al. Stem cell mobilization. Hematology Am Soc Hematol Educ Program. 2003:419-437.

40. Jensen GS, Drapeau C. The use of in situ bone marrow stem cells for the treatment of various degenerative diseases. Med Hypotheses. 2002;59(4):422-428.

41. Eglitis MA, Mezey E. Hematopoietic cells differentiate into both microglia and macroglia in the brains of adult mice. Proc Natl Acad Sci USA. 1997;94(8):4080-4085.

42. Smogorzewska EM, Dukes L, Kuo L, et al. Nucleated red blood cells in normal bone marrow for transplantation. Med Wieku Rozwoj. 2007;11(1):7-11.

43. Herzog EL, Chai L, Krause DS. Plasticity of marrow-derived stem cells Blood. 2003;102(10):3483-3493.

44. Vitry S, Bertrand JY, Cumano A, et al. Primordial hematopoietic stem cells generate microglia but not myelin-forming cells in a neural environment. J Neurosci Off J Soc Neurosci. 2003;23(33):10724-10731.

45. Mezey E, Chandross KJ, Harta G, et al. Turning blood into brain: cells bearing neuronal antigens generated in vivo from bone marrow. Science. 2000;290(5497):1779-1782.

46. Koh SH, Baik W, Noh MY, et al. The functional deficiency of bone marrow mesenchymal stromal cells in ALS patients is proportional to disease progression rate. Exp Neurol. 2012;233(1):472-480. 